\title{
Ports Sustainability: A life cycle assessment of Zero Emission Cargo Handling Equipment
}

\author{
Andrija Vujičić1 ${ }^{*}$ - Nenad Zrnić2 - Boris Jerman ${ }^{3}$ \\ 1 Dunav Insurance Company, Serbia \\ 2 University of Belgrade, Faculty of Mechanical Engineering, Serbia \\ 3 University of Ljubljana, Faculty of Mechanical Engineering, Slovenia
}

\begin{abstract}
The goal of this paper is to present and evaluate the latest trends in the cargo handling equipment (CHE) industry, aimed at mitigating the environmental impact of container terminal operations and contributing to the sustainability of ports. The most common machines for handling containers are described and dealt with separately, with a focus on electric CHE, usually referred to as 'zero emission' CHE. In a separate chapter, recommendations on methodologies suitable for investigation of the environmental footprint of CHE without on-site measuring are reviewed. The life cycle assessment (LCA) methodology as a tool for comparison of conventional and 'zero emission' technology is emphasised with examples. The conventional diesel rubber-tired gantry (RTG) crane and utility tractor rig (UTR) are compared with an electric RTG and UTR using an LCA approach.
\end{abstract}

Keywords: port container terminals, cargo handling equipment, zero emission, rubber-tired gantry, utility tractor rig, life cycle assessment

\section{O INTRODUCTION}

With more than $90 \%$ of global freight moving by containers, container transport industries have an immense influence and role in the global economy. Ports are a core component in the international supply chain and play an enormous role in regional economies; regional development is directly related to the ability of ports to adapt to emerging challenges.

The economic strength behind ports and container terminals unfortunately comes with a heavy environmental burden. The growing port activities and the densely populated cities where most ports are located, combined with already pollution-saturated air and water, are imposing threats to public health and environment in general. Many ports today are considered to be the largest sources of air pollution in coastal cities and awareness of the necessary action for the reduction of pollution has become the matter of public concern. Related research regarding this topic can be found in the work of Cannon [1] and [2].

It is also necessary to note that the environmental footprint of ports is rising to the top of the port authorities' agenda at the same moment an economic downturn has already exerted stress on container operations struggling to remain cost effective.

Emissions in ports come from several different sources. The main pollutants at ports are vessels, harbour craft, cargo-handling equipment (CHE) and trains and heavy vehicles within or near the port. Each source of port emissions is treated using different solutions but with the same goal of reduced environmental impact. From recommendations to solve the problem of cold ironing of vessels by Nikitakos [3] to the 'green' intralogistics investigated by Kartnig et al. [4], the ideal is the zero emission port.

The objective of this paper is to investigate the background of the 'zero emission' concept. The tool used for investigation is the life cycle assessment (LCA) methodology. The two most common machines found at the container terminals, the rubber tired gantry (RTG) crane and the utility tractor rig (UTR), have been selected as an example for a comparison of conventional and 'zero emission' technologies.

\section{CARGO HANDLING EQUIPMENT}

Although the greenhouse gas (GHG) emissions from ports that have adopted strategies to mitigate environmental impact have some effect, $\mathrm{CO}_{2}$ emissions from CHE operations are still rising, according to latest reports from Starcrest [5]. The reasons could be found in the increased rate of container handlings, the modest application of 'clean' technologies, and often weak or absent emission regulation policies for nonroad diesel engines found in CHE.

In port container terminals, containers are ferried around using specially designed cranes and special forklifts, tractors or trucks. The containers are lifted from a marine vessel by a crane and later moved or picked by other crane, handler or forklift. The container can also be transported around the terminal using UTR, which is also known as a 'yard truck'.

Most common in CHE fleets are UTRs, followed by forklifts, handlers and gantry cranes. $\mathrm{CHE}$ is 
conventionally powered by internal combustion engines that are (according to the reports of Starcrest [6]) powered by diesel engines with non-road emission standards in $95 \%$ of cases. Due to the fact that handling loaded containers is an energy-intensive function, CHE is often considered to be one of the most significant sources of air pollution caused by terminal operations.

In this paper, the focus is on the RTG cranes and UTRs, since they are the most common pieces of CHE, accounting for over $55 \%$ of all CHE in container terminals [6]. RTGs are dependent on the support of UTRs for quick container transport across the terminal; a combined evaluation of their environmental impact and operating costs is a common approach in terminal planning, also recommended by Böse [7].

\subsection{Rubber Tired Gantry Crane}

In port container terminals, RTG cranes are used for the movement of shipping containers, once they are placed on to the distribution channels from a vessel. The cranes are powered by a diesel generator set, consisting of a diesel engine coupled with an alternator.

An RTG crane is capable of moving containers weighing up to 50 tonnes at a rate of 20 moves per hour. Since it is one of the largest machines on tires in the world, powered by a large non-road diesel engine, turning it into an eco-friendly machine is a challenging task.

A conventional diesel generator set provides electrical power for the hoist, trolley, and gantry electric motors, as well as for the routine demands of the crane. Utilizing this type of power system on a RTG allows the crane to move independently throughout the container terminal as required by daily port operation. The freedom of movement and the high peak power demand for the hoist motor consume a large amount of fuel and emit significant amounts of GHG.

Today, a variety of technologies and systems are available to reduce fuel consumption and emissions, and improve overall RTG efficiency. They include technologies such as variable-speed generators, flywheel energy storage, hybrid RTGs with regenerative breaking and super or ultra-capacitor technology and electrified 'zero emission' cranes. Most of them are available as retrofits for conventional cranes, but also as new manufactured RTG options.

In the past, electrified RTG (E-RTG) cranes were often avoided due to complicated electric power cable arrays, reduced movability and limited flexibility.
Today E-RTG's disadvantages have been overcome with the cable reel and most recently with a drive-in conductor bar solution with a collector trolley that automatically engages and disengages. Although the main disadvantage remains, i.e. the need to adapt the terminal for electrification, the fact is that with the latest solutions, the environmental advantages of E-RTG are again relevant. For $90 \%$ of operating time, E-RTG cranes use only electricity and use their diesel engines for the remaining $10 \%$ of time, during block changes and maintenance. The manufacturers of E-RTG promise a massive potential for $\mathrm{CO}_{2}$ reduction.

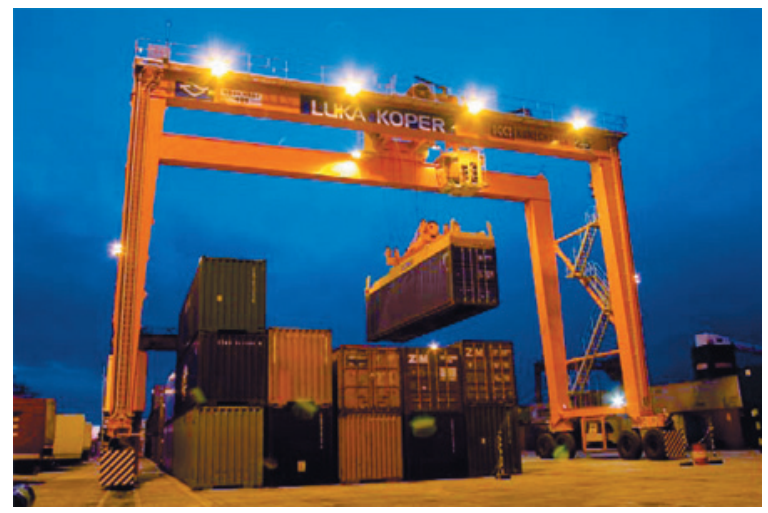

Fig. 1. Rubber Tired Gantry crane

\subsection{Utility Tractor Rigs}

Utility tractor rigs (UTR; often also called terminal tractors, yard trucks or hostlers) are heavy-duty offroad single cab trucks designed for moving cargo containers. They are by far the most common type of CHE used at container terminals [6].

The UTR is connected to a trailer, which it uses to transport containers. In a typical operation, a container is loaded onto a trailer by a piece of CHE, such as a crane, handler or RTG. The UTR then tows the trailer with the container to a destination within the terminal where the container is unloaded by another piece of CHE.

In each use of a crane or handler, the container is ferried around the yard using a UTR. Therefore, UTRs are the most influential category of equipment in terms of fuel consumption and air emissions [6].

In order to mitigate the environmental footprint of UTRs, a wide range of technologies is available with high possibilities of mainstream application. The most common solutions tested at container terminals make use of alternative fuel options (LPG, CNG and biodiesel), hybrid (diesel-electric and dieselhydraulic) and electric drives, often regarded as 'zero emission' UTR. 


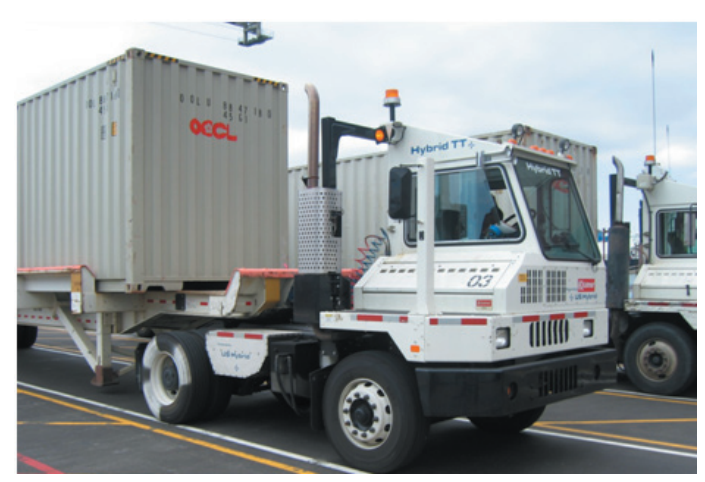

Fig. 2. Utility tractor rig

The long idling periods and stop-and-go movements with bursts of accelerations of UTRs are significant emission sources followed by noise pollution adjacent to affected neighbourhoods. Fortunately, the UTRs' duty cycles are highly predictable and suitable for the application of emission reduction technologies. This generally due to the high levels of idle with up to $50 \%$ of total operating time. The major issue of idling is efficiently resolved with hybrid and electric UTRs, where no energy is used during stops, reducing both exhaust emissions and noise pollution.

One of the latest trends in the CHE industry is the fully electric UTR, which is also referred as 'zero emission' equipment. As with most electric on-road vehicles, the success of this concept is to a significant extent dependant on the efficiency of its batteries. Electric UTRs are available with lead, nickel, and lithium-ion battery packs; . Depending on battery pack sizes, which for UTRs range from 150 to $300 \mathrm{kWh}$, autonomy could be sufficient for two shift operations.

\section{EVALUATION OF CARGO HANDLING EQUIPMENT FOOTPRINT}

In order to understand the environmental impact of container terminals, various models and tools that quantify the relevant emissions can be used or developed. Each model can vary significantly in terms of both complexity and accuracy, as well as time and resources on the other. Furthermore, some methodologies and practices are more suitable for vessels or rail machines than CHE.

The non-modelling approach to create an emission inventory of $\mathrm{CHE}$ is to directly measure emissions or energy consumption. Although it could be considered the most accurate way, it is also the most expensive and time demanding, and can only be performed after the infrastructure is in place. Direct emissions measurement, thus negates early stage planning process, but is more suitable for establishing the baseline inventory.

Therefore, the modelling is more appropriate as a preventive approach, and as support for decision making. The complexity of modelling methodologies can also vary depending on intended use and users, and can also be time and resource consuming if a detailed and validated model is wanted, according to Liu et al. [8]. A simple model for predictions of emissions and energy consumption at terminals can be found in the research of Geerling and Duin [9].

Regardless of which modelling approach is chosen, it enables the prediction of the emissions of any source at port without actually ever visiting facility. This can also be used for the comparison of different types of CHE. The emissions are estimated with developed models and/or inventories for representing CHE technical data, such as rated power, model year, fuel type, annual hours of operation, load data, etc. The average emissions per engine for each equipment type are then multiplied by the number of operating shifts or hours, further by the total number of engines in the CHE group and annual emissions for certain equipment.

The downside of these approaches is that any uncertainty in the baseline parameters can eventually lead to significant uncertainty in the final results of estimated CHE emissions. This is of considerable importance, especially when comparison of any type of CHE is made, since even the slightest aberration in early modelling can result in favouring one piece of equipment over another.

\subsection{The Life Cycle Assessment as Comparison Tool}

Certain pieces of handling equipment have advantages over others and certain terminal configurations (size, average number of handling operations, etc.) are more suitable for certain types of CHE; nevertheless, regarding overall port sustainability, it is necessary to determine which solution or equipment has the smaller environmental footprint [10].

With regards to tools for quantifying the environmental impact of products or process, certain methodologies have advantages over others, but for the sustainability assessment, one of the most appropriate ways is to carry out an LCA. Investigations regarding sustainability assessment via LCA can be found in the research of Pušavec and Kopač [11].

The LCA methodology outlined in ISO 14040 [13] is a quantitative tool for the assessment of the environmental impacts of products and services. 
It is a systematic approach for analysing the entire life cycle stages from material extraction through manufacturing, use and eventually disposal or (preferably) recycling. Therefore, it is often called a 'cradle to grave' analysis.

The application of LCA studies in the field of material handling has caught the attention of the engineering researchers in recent years, but unfortunately little literature on the subject of assessment of CHE is available [14] and [15]. Despite the modest number of published works on assessments of CHE via LCA, there are several facts indicating that this methodology could be used for this purpose.

First, it offers a consistent comparison of the production phase of a machine, via a 'cradle to gate' assessment, the propulsion system and even an alternative fuel solution with a 'well-to-tank' assessment, since an LCA can address the evaluation of the environmental burden of fossil fuels from extraction, refining, transportation, distribution, as well as electricity production. Chester and Horvath [14] often used an LCA for comparison of well-totank emissions related to use of petrol or diesel and electric energy in transport.

Secondly, an LCA offers evaluations based on inventory data without the need for on-site measurements. This makes it a useful tool for both designers and industry, as well as for stakeholders and policy makers.

\section{EXAMPLES OF LIFE CYCLE ASSESSMENT OF CARGO HANDLING EQUIPMENT}

For the purpose of this paper, a comparative LCA of conventional over electric RTG and UTR is conducted. This approach is appropriate when the goal of study is to identify significant issues in each phase of the life cycle of products or production systems that have substantial similarities. Since the chosen models are identical in function and the main difference is the change from diesel to electric technology, only the LCA methodology can respond to the sustainability sensitivities.

\subsection{Life Cycle Assessment Assumptions}

In order to simplify the LCA comparison and avoid possible data uncertainties, certain assumptions and limitations have been made. This is in accordance with the LCA standards and practice, since the intended purpose of the study is solely scientific research and not a commercial one.
The assumptions are made with respect to the operational life of CHE and port terminal experience in order to avoid significant virtualization in the modelling approach. The conventional diesel model of RTG crane and UTR are set as basic models, while other two electric models share over $95 \%$ of the same structure and components (gantry, chassis, wheels, cabin, etc). With the adoption of this modelling principle, most of inventory base of conventional diesel RTG and UTR can be used for evaluation of electric models.

The assessment is divided into life-cycle three phases. First is the production or 'upstream' phase, called 'cradle to gate', which addresses all processes from material extraction and depletion through parts production and model assembly and finally distribution to port terminal. The second is the 'use' phase, referred as 'gate to grave' is the phase with the longest and largest environmental impact. This phase is also addressed with respect to the 'well-totank' principle. The final phase is the scrapping and disposal or recycling of RTG and UTR, called 'end of life'.

The 'cut-off' principle is applied in the manufacturing phase, enabling authors to leave out parts, components and processes that weigh less than $5 \%$ of the total mass of chosen model, or have an insignificant contribution to overall environmental impact.

The Functional Unit (FU) is also defined according to the LCA practice. The FU is set as one operating hour of models at a container terminal, separately described for RTG crane and UTR.

The container terminal location and electric power grid mix are chosen to be an EU port and use an EU-25 power grid mix. This selection is made with respect to software used for LCA study.

The LCA is conducted using holistic balancing software ('GaBi', from the German Ganzheitlichen Bilanzierung) developed by PE International, which is (according to a survey by Cooper and Fava [16]) the most common LCA tool used by over $58 \%$ of surveyed practitioners. In order to provide the most accurate data to a study, the GaBi software inventory data on 'end of life' is compared with results from Zackrisson et al. [17] and Majeau-Bettez et al. [18] who researched lithium-ion battery disposal and recycling. 


\subsection{Life Cycle Assessment Comparison of Rubber Tired Gantries}

The main features of a conventional RTG crane model for an LCA study are the following: total weight of a crane is 115 tonnes; lifting capacity is 40 tonnes; diesel engine displacement is 12 litres; peak power is $300 \mathrm{~kW}$ with $600 \mathrm{kVA} \mathrm{AC} / \mathrm{DC}$ generator.

Once the results of 'upstream' phase of conventional RTG crane model are determined, they are used for electric RTG. The RTG electric solutions are available as retrofits and brand new cranes. The diesel engine is not removed since it is necessary for movement of crane outside of the conductor bar yard. Therefore, the 'upstream' phase of an E-RTG crane differs from a conventional one, only with regard to the impact results of add-on kit parts. The environmental impact of the conversion of container terminal in order to serve the needs of E-RTG is not taken into account, although the contribution to the overall score of electrification is not in doubt.

The FU for the RTG is defined as one operating hour at a container terminal, where $50 \%$ of time is spent for crane movement, $30 \%$ for lifting operations and $20 \%$ for spreader movement. The annual operation time for RTG crane is 5,000 working hours. The life cycle is 15 years.

\subsection{Life Cycle Assessment Comparison of Utility Tractor Rigs}

The main features of the adopted UTR models for LCA study are the following: net and gross weight is 8 and 70 tonnes, respectively; diesel engine displacement is 8 litres with $200 \mathrm{~kW}$ peak power. The main features of an electric UTR are an electric motor with $240 \mathrm{~kW}$ of power and $140 \mathrm{kWh}$ with $320 \mathrm{~V}$ lithium-ion battery pack.
The base model of UTR used for the 'upstream' phase is a conventional diesel UTR. The electric UTR model uses the entire inventory of conventional UTR but, without data for a diesel engine and related components, but with data added for an electric motor and lithium ion battery pack.

The FU for the UTRs is defined as one operating hour at a container terminal (yard work), where $40 \%$ of a time is spent in idling, $35 \%$ of time is related to lower load and $25 \%$ with high load. The annual operation time for UTR is 3,500 working hours. The life cycle is 10 years.

\section{RESULTS}

The obtained emissions inventory and mandatory elements of conventional and electric RTG cranes and UTRs are included in the selection of impact categories in accordance with ISO 14040-44 [13]. Environmental impacts of life cycles are classified and characterised via a problem-oriented approach (midpoint), and the LCIA (life cycle impact assessment) stage is addressed with most common LCIA methods used in Europe and the US.

The first method, the Centre for Environmental Sciences Leiden (CML) has been developed by the Institute of Environmental Sciences from Leiden and is, according to Azapagic [19], the most widelyused and is considered to be the most complete methodology. It uses primarily European data to derive its impact factors. The impact categories for the global warming potential (GWP) and ozone layer depletion are based on IPCC (Intergovernmental Panel on Climate Change) factors. In this paper, the latest version of the CML 2001 is used.

The second impact assessment methodology TRACI (Tool for the Reduction and Assessment of Chemical and Other Environmental Impacts) is developed by the US EPA (United States

Table 1. Life Cycle Impact Assessment of Rubber Tired Gantries - CML method

\begin{tabular}{|c|c|c|c|c|c|c|c|}
\hline CML 2001 & Impact / [unit] & $\begin{array}{c}\text { Global Warming } \\
\text { Potential }\end{array}$ & $\begin{array}{l}\text { Acidification } \\
\text { Potential }\end{array}$ & $\begin{array}{c}\text { Eutrophication } \\
\text { Potential }\end{array}$ & $\begin{array}{l}\text { Ozone Depletion } \\
\text { Potential }\end{array}$ & $\begin{array}{l}\text { Photochemical } \\
\text { Ozone Creation }\end{array}$ & $\begin{array}{c}\text { Radioactive } \\
\text { waste }\end{array}$ \\
\hline Phase & RTG type & {$\left[\mathrm{kg} \mathrm{CO}{ }_{2}\right.$ eq. $]$} & {$\left[\mathrm{kg} \mathrm{SO}_{2}\right.$ eq. $]$} & [kg Phos. Eq.] & [kg R11 eq.] & [kg Ethene eq.] & {$[\mathrm{kg}]$} \\
\hline \multirow{2}{*}{ Cradle to Gate } & diesel & $335,830.77$ & $1,766.85$ & 96.93 & 0.06 & 100.11 & 745.19 \\
\hline & electric & $344,437.66$ & $1,812.51$ & 98.99 & 0.06 & 102.78 & 773.13 \\
\hline \multirow{2}{*}{ Gate to Grave } & diesel & $6,017,597.26$ & $78,635.93$ & $13,547.53$ & 0.00 & $8,382.59$ & 1.86 \\
\hline & electric & $1,462,726.14$ & $12,520.48$ & $1,583.79$ & 0.21 & $1,117.36$ & $2,757.85$ \\
\hline \multirow{2}{*}{ End of Life } & diesel & $-15,843.96$ & -200.51 & 0.00 & 0.00 & -21.15 & -1.86 \\
\hline & electric & $-13,625.81$ & -172.43 & 0.00 & 0.00 & -18.19 & -1.60 \\
\hline \multirow{2}{*}{ Cradle to Grave } & diesel & $6,337,584.07$ & $80,202.27$ & $13,644.46$ & 0.06 & $8,461.55$ & 745.19 \\
\hline & electric & $1,793,537.99$ & $14,160.56$ & $1,682.78$ & 0.26 & $1,201.95$ & $3,529.38$ \\
\hline
\end{tabular}


Table 2. Life Cycle Impact Assessment of Rubber Tired Gantries - TRACl method

\begin{tabular}{|c|c|c|c|c|c|}
\hline TRACl & Impact/[unit] & Acidification Air & Eutrophication Water & Global Warming Air & Human Health Criteria Air Point Source \\
\hline Phase & RTG type & [mol H+ eq.] & [kg N eq.] & [kg CO${ }_{2}$ eq.] & [kg PM 2.5 eq.] \\
\hline \multirow{2}{*}{ Cradle to Gate } & diesel & 933.58 & 24.00 & $335,818.04$ & 199.23 \\
\hline & electric & 934.65 & 24.00 & $343,206.03$ & 199.23 \\
\hline \multirow{2}{*}{ Gate to Grave } & diesel & $4,450,249.43$ & $4,616.07$ & $6,169,662.32$ & $40,011.83$ \\
\hline & electric & $698,156.07$ & 530.17 & $1,449,098.83$ & $21,003.59$ \\
\hline \multirow{2}{*}{ End of Life } & diesel & $-1,335.00$ & -1.87 & $-16,128.50$ & -2.02 \\
\hline & electric & -376.00 & 2.67 & $-14,135.00$ & 0.01 \\
\hline \multirow{2}{*}{ Cradle to Grave } & diesel & $4,449,848.01$ & $4,638.20$ & $6,489,351.86$ & $40,209.04$ \\
\hline & electric & $698,714.72$ & 556.84 & $1,778,169.87$ & $21,202.82$ \\
\hline
\end{tabular}

Table 3. Life Cycle Impact Assessment of Utility Tractor Rigs - CML method

\begin{tabular}{|c|c|c|c|c|c|c|c|}
\hline CML 2001 & Impact / [unit] & $\begin{array}{l}\text { Global Warming } \\
\text { Potential }\end{array}$ & $\begin{array}{c}\text { Acidification } \\
\text { Potential }\end{array}$ & $\begin{array}{c}\text { Eutrophi-cation } \\
\text { Potential }\end{array}$ & $\begin{array}{l}\text { Ozone Depletion } \\
\text { Potential }\end{array}$ & $\begin{array}{l}\text { Photochem-ical } \\
\text { Ozone Creation }\end{array}$ & $\begin{array}{c}\text { Radioactive } \\
\text { waste }\end{array}$ \\
\hline Phase & UTR type & [kg CO${ }_{2}$ eq. $]$ & [kg SO${ }_{2}$ eq.] & [kg Phos. Eq.] & [kg R11 eq.] & [kg Ethene eq.] & {$[\mathrm{kg}]$} \\
\hline \multirow{2}{*}{ Cradle to Gate } & diesel & $36,174.60$ & 191.95 & 8.66 & 0.01 & 11.21 & 117.45 \\
\hline & electric & $68,024.60$ & 360.95 & 25.00 & 0.02 & 21.08 & 220.86 \\
\hline \multirow{2}{*}{ Gate to Grave } & diesel & $746,884.86$ & $9,760.85$ & $1,681.68$ & 0.00 & $1,040.53$ & 0.00 \\
\hline & electric & $377,300.00$ & $2,002.00$ & 90.30 & 0.09 & 116.90 & $1,225.00$ \\
\hline \multirow{2}{*}{ End of Life } & diesel & 246.67 & 1.31 & 0.06 & 0.00 & 499.65 & 0.80 \\
\hline & electric & $4,950.20$ & 26.27 & 4.17 & 0.15 & 2.47 & 1.14 \\
\hline \multirow{2}{*}{ Cradle to Grave } & diesel & $783,306.12$ & $9,954.11$ & $1,690.40$ & 0.01 & $1,551.39$ & 118.25 \\
\hline & electric & $450,274.80$ & $2,389.21$ & 119.47 & 0.26 & 140.45 & $1,447.00$ \\
\hline
\end{tabular}

Table 4. Life Cycle Impact Assessment of Utility Tractor Rigs - TRACl method

\begin{tabular}{|c|c|c|c|c|c|}
\hline TRACI & Impact/[unit] & Acidification Air & Eutrophication Water & Global Warming Air & $\begin{array}{l}\text { Human Health Criteria } \\
\text { Air Point Source }\end{array}$ \\
\hline Phase & UTR type & [mol H+ eq.] & [kg N eq.] & [kg CO ${ }_{2}$ eq.] & {$\left[\mathrm{kg} \mathrm{PM}_{2.5}\right.$ eq. $]$} \\
\hline \multirow{2}{*}{ Cradle to Gate } & diesel & 101.48 & 2.14 & $36,501.96$ & 28.46 \\
\hline & electric & 188.06 & 29.00 & $73,022.56$ & 75.00 \\
\hline \multirow{2}{*}{ Gate to Grave } & diesel & $553,808.82$ & 574.44 & $767,780.20$ & $4,979.25$ \\
\hline & electric & $288,893.49$ & 299.66 & $387,926.71$ & $2,566.62$ \\
\hline \multirow{2}{*}{ End of Life } & diesel & 166.14 & 1.31 & 230.33 & 0.25 \\
\hline & electric & $3,790.28$ & 26.27 & $5,089.60$ & 109.59 \\
\hline \multirow{2}{*}{ Cradle to Grave } & diesel & $554,076.44$ & 577.90 & $804,512.49$ & $5,007.96$ \\
\hline & electric & $292,871.83$ & 354.92 & $466,038.87$ & $2,751.22$ \\
\hline
\end{tabular}

Environmental Protection Agency). The detail that is developed by that US EPA has influenced the wide use of this methodology in North America. It differs from the CML methodology because the data comes primarily from US sources. In this way, the results of the paper are equally applicable to EU and US ports, since RTG cranes and UTRs can be found in operation in the ports of both areas.

Other abbreviations used further in the paper are: acidification potential (AP), eutrophication potential (EP), ozone depletion potential (ODP), photochemical ozone creation potential (POCP) and human health criteria air-point source (HHCAPS).

\subsection{Life Cycle Assessment results of Rubber Tired Gantries}

The results show the modest contribution of the 'cradle-to-gate' phase to the overall impact, which is extremely common for products with long life cycles, especially large fossil fuel-powered machines. The raw material depletion and energy consumption for manufacturing process of approx. $1.8 \times 10^{6} \mathrm{MJ}$ are the most significant issues of the 'cradle to gate' phase. The differences between the environmental impacts of the production phase of conventional and electric RTG is approximately $2.5 \%$. This ratio is less than the 'cut off' criteria assumption of $5 \%$, underlining that 
difference in production of E-RTG over conventional power has little additional environmental consequence.

The 'gate to grave' or 'use' phase is predominantly shaped by the energy intensity of FU and the long life cycle. The differences between conventional and electric RTG in terms of GHG emissions and LCIA are significant. The results show an over $70 \%$ of $\mathrm{CO}_{2}$ eq. reduction for electric RTG, which could be attributed to the use of the EU-25 power grid mix from which 539 grams of $\mathrm{CO}_{2}$ eq. per $\mathrm{kWh}$ is emitted. The result would vary considerably in cases of different footprints for other power plants (i.e. coal versus wind energy).

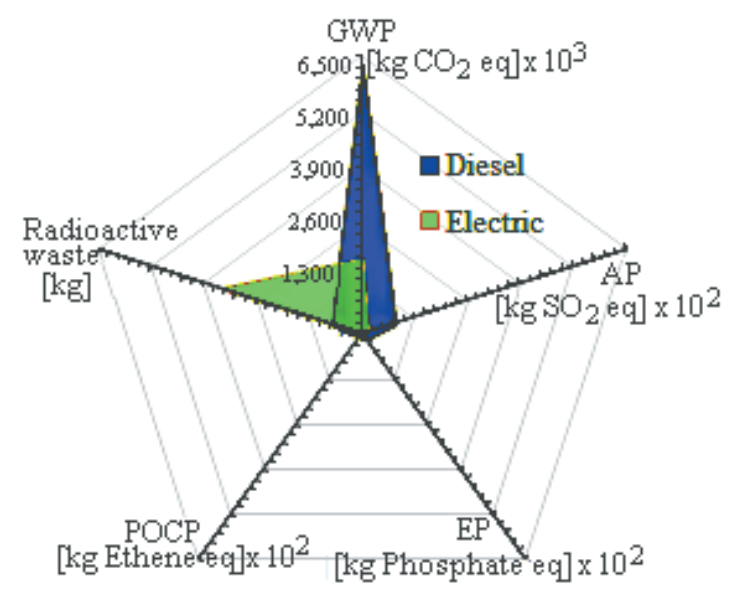

Fig. 3. Life cycle impact of Rubber Tired Gantries - CML method

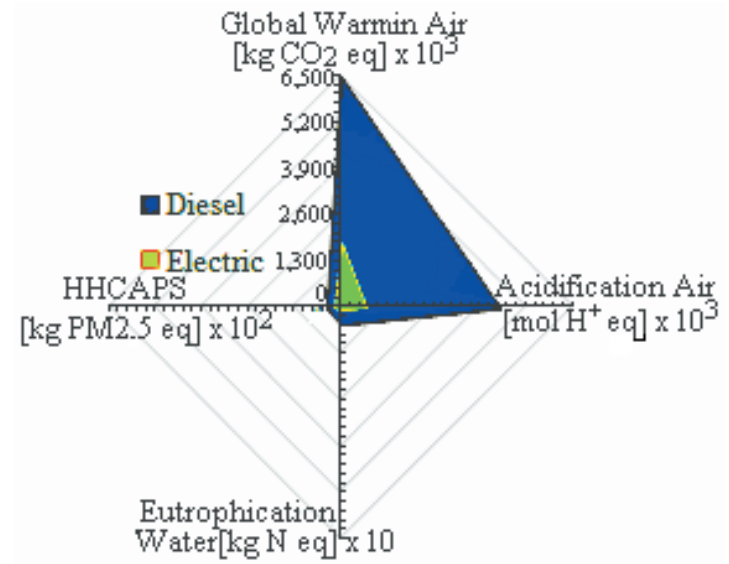

Fig. 4. Life cycle impact of Rubber Tired Gantries - TRACl method

The 'end of life' phase shows that the potential LCA environmental impact could be positive (negative values in Tabs 1 and 2). This is the case with recycling, when energy savings are greater than disposal of leftovers. Since the steel used for gantry and spreader weights almost 100 tonnes and is highly recyclable, no negative effects can be associated with this phase.

\subsection{Life Cycle Assessment Results of Utility Tractor Rigs}

The 'cradle to gate' phase of diesel and electric UTRs show substantial differences in the enginemanufacturing process. The environmental impact of lithium-ion battery pack production is much greater than of conventional diesel engines. The GWP for a $140 \mathrm{kWh}$ battery pack of the chosen electric UTR model is approx. $37,000 \mathrm{~kg}$ of $\mathrm{CO}_{2}$ eq., while for an 8-litre 6-cylinder diesel engine it is less than $3,000 \mathrm{~kg}$ of $\mathrm{CO}_{2}$ eq. This proportion is a significant issue that has to be taken in to consideration.

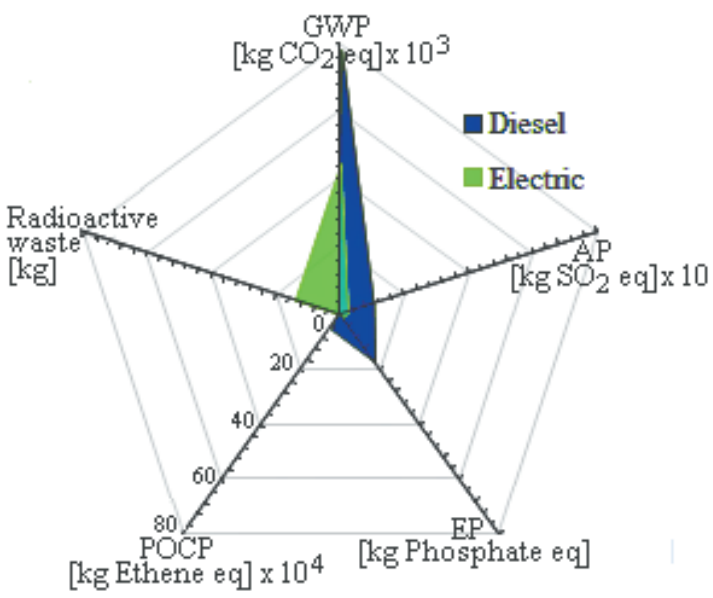

Fig. 5. Life cycle impact of Utility Tractor Rigs - CML method

The results of the 'gate to grave' phase show a similar trend of lesser environmental impact of electric UTR, as with RTG cranes. In case of electric UTR, the GWP is up to $50 \%$ reduced over its entire life cycle. Again, this is with the EU-25 power grid mix and the results could vary depending on power plant footprint. An additional downside that can slightly diminish the efficiency of electric UTR may be the life cycle of lithium-ion battery packs. They lose some capacity potential after a certain number of recharges, i.e. between 1,500 and 2,500 working hours. Since the life cycle of UTRs is usually longer $(3,500$ hours in this study), one replacement in order to maintain UTR's power capacity at maximum level can be expected. The additional case of their replacement during a 10year life cycle of UTR is not part of the introduced LCA, but this scenario is presented within a 'what if' analysis.

The 'end of life' phase is also influenced with lithium ion batteries disposal. The GWP impact of the disposal of a $140 \mathrm{kWh}$ lithium ion battery pack is 
close to $5,000 \mathrm{~kg}$ of $\mathrm{CO}_{2}$ eq., while the diesel engine is $300 \mathrm{~kg}$ of $\mathrm{CO}_{2}$ eq. It is necessary to underline that life cycle of diesel engine with environmentally undemanding overhauling can easily be extended by an additional 5 years.

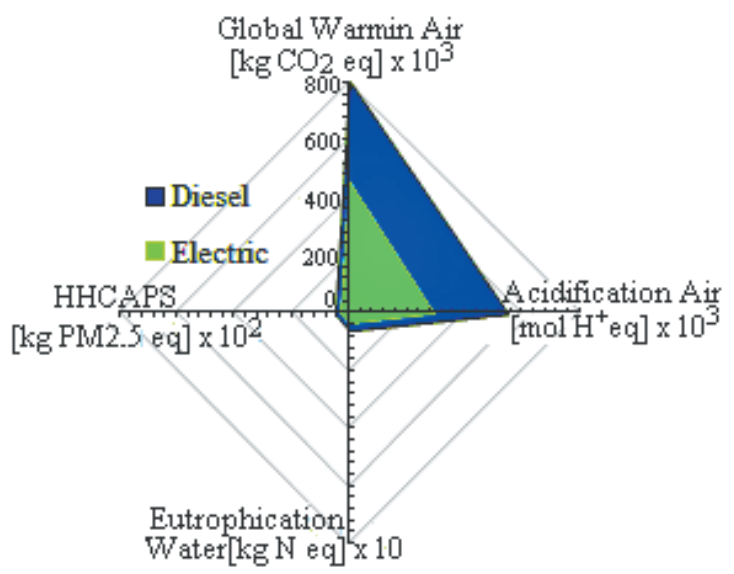

Fig. 6. Life cycle impact of Utility Tractor Rigs - TRACI method

\subsection{What-If Analysis}

Because the selection of the power grid mix can, due to nature of LCA, provide entirely different results, a short 'what if' analysis is conducted. In order not to overextend the comparison of data, only GWP is taken into account. The calculation for the replacement of a lithium ion battery pack of an electric UTR after 5 years is also shown in Fig. 7.

The assumptions made for comparison of environmental impacts of UTRs presented in Fig. 3 as follows:

- Electric 1; refers to results from LCA, without a battery change and EU-25 power grid mix with GWP of $0.539 \mathrm{~kg}$ of $\mathrm{CO}_{2}$ eq. per $\mathrm{kWh}$;

- Electric 2; the same as above with a battery replacement (disposal of old batteries and entire life cycle of new batteries);

- Electric 3; for this UTR, the power grid mix is adapted to be the world average with GWP of $0.749 \mathrm{~kg}$ of $\mathrm{CO}_{2}$ eq. per $\mathrm{kWh}$; The battery replacement is also taken into account;

- Electric 4; The power grid mix is an average GWP for coal power plants approximated to $1 \mathrm{~kg}$ of $\mathrm{CO}_{2}$ eq. per $\mathrm{KWh}$;

- Diesel; results from LCA study.

The analysis shows that electric UTR has lower GWP only up to the level of $0.9 \mathrm{~kg}$ of $\mathrm{CO}_{2}$ eq. per $\mathrm{kWh}$ of electric energy. In the case of coal-burning power plants, the emissions of a conventional diesel UTR are only replaced with a similar level of GWP of electric UTR. If the additional environmental impact of battery replacement is taken into account, as with case of presented electric UTR no. 4, the overall results are actually worse than conventional dieselburning UTR.

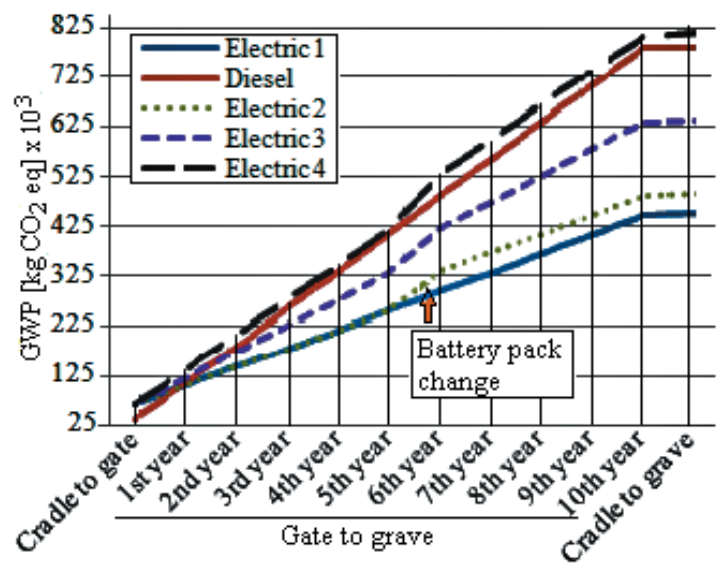

Fig. 7. Life cycle impact of Utility Tractor Rigs depending on power grid mix

\section{CONCLUSIONS}

The efforts of the CHE industry in providing ports and container terminals with environmentally more efficient technologies are becoming increasingly visible. Almost every piece of CHE today is offered with some solution for the reduction of emissions and energy consumption, from alternative fuels and hybrid technology, to promising 'zero emission' concepts.

The 'zero emission' concept applied to the RTG crane and UTR as the core of CHE is investigated using LCA methodology. The entire life cycles of a conventional diesel RTG crane and UTR are compared with electric ones in order to reveal any sustainability sensitivities that are common with energy source transitions.

In this respect, the results of LCA present the electrification of CHE as a feasible and sustainable solution aimed mitigating the environmental impact of ports. The transition from diesel to electric handling equipment is a step forward, although from the LCA perspective, 'zero emission' operations are impossible to achieve.

The 'gate-to-grave' phase of electric CHE shows significant reductions in GWP, AP and EP with differences between RTG and UTR. Based on the comparative LCA, it has been proved that electrification of $\mathrm{CHE}$ has a greater potential in reducing the emissions and energy consumption of larger and heavier equipment. 
The energy-consuming work operations of RTG cranes are more suitable for electrification despite the remaining 'tailpipe' emissions during block changes. The obtained results show that due to the long life span and the large number of annual operating hours GWP, savings cannot be derived from any power grid mix scenario.

However, electric UTRs have no 'tailpipe' emissions but are noticeably influenced by the environmental burden of lithium ion batteries. The life span of UTRs can be twice longer than the life span of batteries necessary to provide stored energy, and their replacement along with different power grid mix scenario than the one used in the LCA can jeopardize the emission reduction potential of electric UTRs.

The LCA has proved itself to be a valuable tool for the comparison of such complex products as the CHE. It offers a systematic approach for sustainability evaluations of life cycles of conventional and new technologies. However, in order to avoid any serious data inventory uncertainties (often pointed out by LCA critics), a random comparison of on-site measurements results with functional unit assumptions is recommended.

\section{ACKNOWLEDGMENT}

A part of this research is supported by the bilateral project No. 651-03-1251/2012-09/50 for scientific cooperation between Serbia and Slovenia.

\section{REFERENCES}

[1] Cannon, J.S. (2008). U.S. Container Ports and Air Pollution: A Perfect Storm. Energy Futures Inc., Boulder.

[2] Cannon, J.S. (2009). Container Ports and Air Pollution. Energy Futures Inc., Boulder.

[3] Nikitakos, N. (2012). Green Logistics - The concept of Zero Emissions Port. FME Transactions, vol. 40, no. 4, p. 201-206.

[4] Kartnig, G., Grösel, B., Zrnić, N. (2012). Past, state of the art and future of intralogistics. FME Transactions, vol. 40, no. 4, p. 193-200.

[5] Starcrest (2012). The Port of Los Angeles: Inventory of Air Emissions for Calendar Year 2011. Starcrest Consulting Group, Long Beach.

[6] Starcrest (2008). San Pedro Bay Ports: Emissions Forecasting Methodology and Results. Starcrest Consulting Group, Poulsbo.

[7] Böse, J.W. (2011). Handbook of Terminal Planning, Springer, New York, DOI:10.1007/978-1-4419-8408-1.

[8] Liu, C.I., Jula, H., Ioannou, P.A. (2002). Design, simulation, evaluation of automated container terminals. IEEE Transactions on Intelligent
Transportation Systems, vol. 3, no. 1, p. 12-16, DOI:10.1109/6979.994792.

[9] Geerlings, H., Duin, R. (2011). A new method for assessing $\mathrm{CO}_{2}$-emissions from container terminals: a promising approach applied in Rotterdam. Journal of Cleaner Production, vol. 19, no. 6-7, p. 657-666, DOI:10.1016/j.jclepro.2010.10.012.

[10] Zrnić, N., Vujičić, A. (2012). Evaluation of environmental benefits of CHE emerging technologies by using LCA. 12th International Material Handling Research Colloquium, Conference Proceedings, p. 1628.

[11] Pušavec, F., Kopač, J. (2011). Sustainability assessment: cryogenic machining of Inconel 718. Strojniški vestnik - Journal of Mechanical Engineering, vol. 57, no. 9, p. 637-647, DOI:10.5545/sv-jme.2010.249.

[12] Ostad, H., Collado-Ruiz D. (2011). Tool for the environmental assessment of cranes based on parameterization. International Journal of Life Cycle Assessment, vol. 16, no. 5, p. 392-400, DOI:10.1007/ s11367-011-0280-z.

[13] ISO 14040, (2006). ISO Report 14040 Environmental Management - Life Cycle Assessment, Principles and Framework. International Organization for Standardization, Geneva.

[14] Kim, J., Rahimi, M., Newell, J. (2012). Life-cycle emissions from port electrification: A case study of cargo handling tractors at the port of Los Angeles. International Journal of Sustainable Transportation, vol. 6 no. 6, p. 321-337, DOI:10.1080/15568318.2011 .606353 .

[15] Chester, M.V., Horvath, A. (2009). Environmental assessment of passenger transportation should include infrastructure and supply chains. Environmental Research Letters, vol. 4. no. 9, p. 1-8, DOI:10.1088/1748-9326/4/2/024008.

[16] Cooper, J.S., Fava, J.A. (2006). Life cycle assessment practitioner survey - Summary of results. Journal of Industrial Ecology, vol. 10, no. 4, p. 12-14, DOI:10.1162/jiec.2006.10.4.12.

[17] Zackrisson, M., Avellána, L., Orlenius, J. (2010). Life cycle assessment of lithium-ion batteries for plug-in hybrid electric vehicles - Critical issues. Journal of Cleaner Production, vol. 18, no. 15, p. 1519-1529, DOI:10.1016/j.jclepro.2010.06.004.

[18] Majeau-Bettez, G., Hawkins, T., Strømman, A. (2011). Life cycle environmental assessment of lithiumion and nickel metal hydride batteries for plug-in hybrid and battery electric vehicles. Environmental Science \& Technology, vol. 45, no. 10, p. 4548-4554, DOI:10.1021/es103607c.

[19] Azapagic, A, (2010). Life cycle assessment as a tool for sustainable management of ecosystem services, in Harrison, R.M., Hester, R.E. (eds.), Ecosystem services. RSC Publishing, Cambridge, p. 140-168, DOI:10.1039/9781849731058-00140. 